\title{
Improvement in peripheral lung lesion evaluation and management requires ongoing advances in bronchoscopy
}

\author{
Ajay Wagh ${ }^{1 \wedge}$, Elliot $\mathrm{Ho}^{2 \wedge}$ \\ ${ }^{1}$ Section of Pulmonary and Critical Care Medicine/Interventional Pulmonology, Department of Medicine, The University of Chicago, Chicago, \\ IL, USA; ${ }^{2}$ Section of Pulmonary and Critical Care Medicine/Interventional Pulmonology, Department of Medicine, Loma Linda University, Loma \\ Linda, CA, USA \\ Correspondence to: Ajay Wagh. Division of Interventional Pulmonology, The University of Chicago, 5841 S Maryland Ave, Chicago, IL 60637, USA. \\ Email: awagh@medicine.bsd.uchicago.edu. \\ Comment on: de Ruiter QMB, Fontana JR, Pritchard WF, et al. Endovascular steerable and endobronchial precurved guiding sheaths for \\ transbronchial needle delivery under augmented fluoroscopy and cone beam CT image guidance. Transl Lung Cancer Res 2021;10:3627-44.
}

Submitted Sep 02, 2021. Accepted for publication Sep 18, 2021.

doi: $10.21037 /$ tlcr-21-707

View this article at: https://dx.doi.org/10.21037/tlcr-21-707

We have read the recently published article "Endovascular steerable and endobronchial precurved guiding sheaths for transbronchial needle delivery under augmented fluoroscopy and cone beam CT image guidance" by de Ruiter and colleagues with great interest. We want to congratulate the authors on this successful submission and offer a few comments regarding the practical implications of using non-endoscopic guiding sheath technology for the use of peripheral pulmonary lesion (PPL) evaluation.

PPL diagnostic methods have been advancing remarkably over the last two decades. More PPLs and nodules are being identified due to the updated lung cancer screening guidelines (1). More recently, advances in diagnostic bronchoscopy have been made in the arena of electromagnetic navigation bronchoscopy (ENB) as well as in the use of advanced imaging techniques, including augmented fluoroscopy (AF) and cone beam CT (CBCT). A recent systematic review and meta-analysis by Folch and colleagues found that the pooled sensitivity of ENB was $77 \%$ (with most studies being performed with the superDimension ${ }^{\circledR}$ system) (2). While more robotic assisted bronchoscopy (RAB) studies are pending, a recently published multicenter pilot and feasibility study by Chen and colleagues utilizing the Monarch ${ }^{\circledR}$ robotic bronchoscope platform (including ENB, radial probe ultrasound, and fluoroscopy) resulted in a $96.2 \%$ lesion localization (3). Pritchett and colleagues retrospectively reviewed data on 75 patients (93 lesions with a median size of $16 \mathrm{~mm}$ ) where ENB along with CBCT was utilized for the diagnosis of pulmonary lesions and found that overall diagnostic yield was $83.7 \%$ (4). Therefore, based on the results of these recent studies, we anticipate that sensitivity and diagnostic yield of peripheral bronchoscopy will continue to improve with technological advancement.

The authors' approach for endobronchial access to PPLs using guide sheaths without bronchoscopy potentially risks incomplete evaluation as well as the ability to manage any possible airway bleeding. When navigating the airway, visualization is important to ensure safe passage of the bronchoscope and its instruments without airway trauma. Albeit the risk is low, airway bleeding as a result of transbronchial biopsy has been reported to be $2.8 \%$ (5). Our current approach to controlling airway bleeding is to wedge the sheath of the bronchoscope into a segmental or sub-segmental airway. During active bleeding, we typically apply cold saline via the bronchoscope followed by continuous suctioning in a wedged position to collapse the distal airway and tamponade the bleed. Furthermore, airway anatomy may not always be clear on CT imaging if impacted by mucus or debris. Bronchoscopic visualization

^ ORCID: Ajay Wagh, 0000-0003-3402-0272; Elliot Ho, 0000-0003-0333-6709. 
is often needed when manipulating across bends of the distal carinas and traversing into the distal airways. This is especially important when there are complicated airways, such as airway strictures, extrinsic compression, and airway tortuosity. Airway visualization is also important during needle deployment because there are times when small adjustments are needed to compensate for respiratory motion. Additionally, the bronchoscope can also be used to leverage a tool into a lesion using flexion. Lastly, without bronchoscopic visualization, diagnosis of endobronchial lesions may be missed.

One of the most valuable assets of bronchoscopic sampling of PPLs has been the ability to utilize endobronchial ultrasound (EBUS) to evaluate and sample mediastinal and hilar lymph nodes for lung cancer staging in the same setting. The use of EBUS to stage lung cancer has robust supportive data and is a guideline recommendation by the American College of Chest Physicians (ACCP) (6). Such mediastinal lymph node assessment using nonendoscopic guide sheath technology and AF or CBCT could be feasible, but likely would add a significant amount of exposure to ionizing radiation.

The authors do mention in their discussion that additional bronchoscopic evaluation may be required for pre- and post-guide sheath biopsy. Certainly, if advanced bronchoscopic navigation technology is unavailable at a particular institution, there may be a role for the use of nonendoscopic guide sheath technology in the evaluation of PPLs. However, considering the importance of lymph node evaluation and the value of optics, we believe that nonbronchoscopic biopsy of lung lesions by way of CT and AF guided sheaths alone is not a replacement for bronchoscopic evaluation. Therefore, this approach would be suboptimal for lung cancer assessment, especially if a bronchoscopy would be required for post-procedure airway assessment and for mediastinal staging. We do believe there is utility in $\mathrm{AF}$ and $\mathrm{CBCT}$ in reducing CT-body divergence. However, this technology is currently applied in advanced diagnostic bronchoscopy. While this study was well performed and gives insight into the possible use of endobronchial guiding sheaths as a means for biopsy of PPLs by using advanced imaging, we believe it is best to focus efforts on improving access to advanced technology and imaging modalities for bronchoscopists to improve the diagnosis and management of PPLs.

\section{Acknowledgments}

Funding: None.

\section{Footnote}

Provenance and Peer review: This article was commissioned by the editorial office, Translational Lung Cancer Research. The article did not undergo external peer review.

Conflicts of Interest: Both authors have completed the ICMJE uniform disclosure form (available at https://dx.doi. org/10.21037/tlcr-21-707). Both authors report consulting fees received from Noah Medical.

Ethical Statement: The authors are accountable for all aspects of the work in ensuring that questions related to the accuracy or integrity of any part of the work are appropriately investigated and resolved.

Open Access Statement: This is an Open Access article distributed in accordance with the Creative Commons Attribution-NonCommercial-NoDerivs 4.0 International License (CC BY-NC-ND 4.0), which permits the noncommercial replication and distribution of the article with the strict proviso that no changes or edits are made and the original work is properly cited (including links to both the formal publication through the relevant DOI and the license). See: https://creativecommons.org/licenses/by-nc-nd/4.0/.

\section{References}

1. Meza R, Jeon J, Toumazis I, et al. Evaluation of the Benefits and Harms of Lung Cancer Screening With LowDose Computed Tomography: Modeling Study for the US Preventive Services Task Force. JAMA 2021;325:988-97.

2. Folch EE, Labarca G, Ospina-Delgado D, et al. Sensitivity and Safety of Electromagnetic Navigation Bronchoscopy for Lung Cancer Diagnosis: Systematic Review and Metaanalysis. Chest 2020;158:1753-69.

3. Chen AC, Pastis NJ Jr, Mahajan AK, et al. Robotic Bronchoscopy for Peripheral Pulmonary Lesions: A Multicenter Pilot and Feasibility Study (BENEFIT). Chest 2021;159:845-52.

4. Pritchett MA, Schampaert S, de Groot JAH, et al. Cone- 
Beam CT With Augmented Fluoroscopy Combined With Electromagnetic Navigation Bronchoscopy for Biopsy of Pulmonary Nodules. J Bronchology Interv Pulmonol 2018;25:274-82.

5. Pue CA, Pacht ER. Complications of fiberoptic bronchoscopy at a university hospital. Chest

Cite this article as: Wagh A, Ho E. Improvement in peripheral lung lesion evaluation and management requires ongoing advances in bronchoscopy. Transl Lung Cancer Res 2021;10(9):3694-3696. doi: 10.21037/tlcr-21-707
1995;107:430-2.

6. Wahidi MM, Herth F, Yasufuku K, et al. Technical Aspects of Endobronchial Ultrasound-Guided Transbronchial Needle Aspiration: CHEST Guideline and Expert Panel Report. Chest 2016;149:816-35. 